\title{
Six Ways Parents can Support their Children with the Outbreak of Coronavirus
}

\author{
Barhoumi M* \\ Departement de Physique, Universit'e de Monastir, Tunisia
}

*Corresponding author: Barhoumi M, Departement de Physique, Laboratoire de la Matiere Condens'ee et des Nanosciences (LMCN), Universit'e de Monastir, Faculte des Sciences de Monastir, Avenue de l'Environnement, 5019 Monastir, Tunisia.

To Cite This Article: Barhoumi M. Six Ways Parents can Support their Children with the Outbreak of Coronavirus. Am J Biomed Sci \& Res. 2021 - 11(6). AJBSR.MS.ID.001694. DOI: 10.34297/AJBSR.2021.11.001694.

Received: 阱 January 15, 2020; Published: 阱 February 10, 2021

\begin{abstract}
Up to the moment, the Coronavirus still kills many people, especially those over fifty years old. Also, this virus continues to devastate the entire world economy. More than that, it affected everything even the children's psyche was not immune from it. Here in this study that we did, we provide many tips for people on how to deal with their children to avoid the psychological impact of illness on them.
\end{abstract}

Keywords: COVID-19; SARS-CoV-2; Children; Psychological effects

\section{Introduction}

Before starting to provide advice to avoid the psychological trauma $[1,2]$ of the virus to children. Let's give a glimpse of the virus and how it spreads. A new virus called severe acute respiratory syndrome (SARS) $[3,4]$ was discovered as a cause of an outbreak of a disease that began in China in 2019. The resulting disease is called Coronavirus disease in 2019 (COVID-19). In March 2020, the World Health Organization (WHO) [5,6] declared it classified COVID-19 as a pandemic. Public health groups monitor the pandemic and publish updates online, including the US Centers for Disease Control and Prevention (CDC) and the World Health Organization. These groups also issued recommendations on preventing the spread of the virus. The virus is still spreading widely without stopping, it did not even take a break, but rather expanded and included other regions. We have noticed that one of the factors of this spread is the people's disdain and indifference to the situation until it has become today a catastrophic situation in the fullest sense of the word. The best evidence for this is the number of injuries recorded by Spain, where the number exceeded the threshold of one million. France also has recorded thousands of injuries every day. More than that in Germany so far, on January 12, 2021, more than a thousand deaths per day are recorded. We note that the reason people disdain this deadly disease is their lack of belief in the existence of a disease in the first place. But they quickly believe when they are injured or injured and losing a loved one. Knowing that this pandemic has killed politicians and great artists, such as the senior Palestinian Commissioner "Saber Erekat". And US president Donald Trump, who recently recovered from it. Below we explain, according to our experience, how the virus works: If we realize how it works, we will be able to win the battle against it because it is not a living organism like a bacterium $[7,8]$, but rather a DNA that seeks to be a living being. The goal of the virus is to reach the lung, because it is the only place it can take, considering it contains the oxygen that the virus needs to live. Once the virus enters the throat, it receives a cyclone of saliva, which forces it to enter the stomach. Thus the stomach can eliminate it. On the other hand, this virus will stick to the throat wall as long as possible, and thus the person will feel pain in the throat. If this virus absorbs all the saliva, the throat will become dry. Thus, the disease moves to the lung. Here the patient has to drink a lot of hot water. At this moment, the mind realizes that the body has undergone an attack, and thus the body raises its temperature in order to kill the virus. Here, the patient must drink water, citrus and greens to help the body against this virus. You can also help 
the body by eating the mixture between the citrus and olive oil. However, if this system fails, the virus will multiply inside the body. Note that the COVID-19 can survive on plastic and stainless-steel surfaces at various times. But the question that arises, which is do we have to tell the children all these details and explain them gently so as not to affect them? This review briefly discusses the tips on how you can help your children deal with the amount of feelings they are feeling right now.

\section{Tips to Avoid the Psychological Trauma of the Virus to Children}

There are few studies [9-13] that have looked at the psychological effects that the virus causes on children. Coronavirus is associated with feelings such as anxiety, stress, and suspicion. And those feelings come intense with all children of all ages. Although children deal with these feelings in different ways, if your child faces school closures, cancellation of activities, and separation from friends, he needs your love and supports more than ever. Here, we recommend that you follow the following tips: parents should remain calm while they start talking about Coronavirus, and about the important role children can play in maintaining their health. Your children (and you too) should prepare for the possibility of developing symptoms like those of a cold or the common flu. And tell them that they don't have to be overly afraid of this. Parents should encourage children to tell them if they feel unwell, or that they are worried about the virus so that parents can help. Adults should understand children's feelings of anger and anxiety over COVID-19, as it is normal (Figure 1). Confirm over and over to your children that the disease caused by infection with Covid-19 will usually have average symptoms, especially in children and young adults. It is important to remember that many of the symptoms of Covid-19 can be treated, from this point we can remind our children that there are many meaningful things we can do to keep ourselves and others safe, and to feel that we can control the situation and its circumstances: such as washing hands frequently, not touching our face and applying physical distancing. Another thing we can do is expand their vision, such as telling them: listen to me, I know you are very worried about getting infected, but what we ask you-like to wash your hands and stay at home-aims in part to take care of the members of our community. We care about our neighbours, too. Besides, children need a chart. This is the goal. And what we need to do, and quickly, is to make plans so that we can each spend our day right. I highly recommend that parents make sure they have a plan to spend their day in this guarantees a play time where the child can use their phone to communicate with their friends. At the same time, there should be hours without technology and some time to help out with the housework. We have to keep what we value most and make plans to continue with it. Children will relax a lot if their day is planned, they know when to work and when to play. We also suggest getting your children to join you in what you do: "For children 10-11 or older, I will ask the child to help me prepare for their day. I allude to them the things that should be included in their day, and then I work with them in what they do". As for the younger children and based on who will remain at home (I am fully aware that in some cases it will not be possible for both parents to stay at home), this parent should arrange matters according to the priorities, such as completing the homework and tasks required. For some families, their children prefer to do these things at the beginning of the day, while other families prefer their children to do so after a period of waking up and eating breakfast together. As for the parents who cannot supervise their children, they should arrange with the nanny the best plan for their children. Let your children express their feelings with the closure of schools, activities, parties, sports matches, and activities were cancelled, so children were disappointed with losing what they used to be due to Corona disease (Covid-19). Here we advise that we understand their grief. For teenagers, these things are a major loss in their lives. And it is only great for them because we measure it by our lives and experiences. Support them, and never be surprised by their extreme sadness and frustration because of the things they lost and are crying them now. When you think they are experiencing these feelings, your sympathy and support for them is the correct behaviour in this case. Moreover, check what they hear with them there is a lot of misleading information circulating about the Corona virus (that causes Covid-19). Find what your child hears or thinks is true. Informing your children of the facts is not enough. If they take inaccurate information, and you are ignorant of what is going on in their minds and do not correct what they have drawn, then perhaps they combined the recent information that you told them with the old information that they know. Find what your children know to make a starting point for getting them into the right course. And if they have questions that you don't know are, instead of guessing, take advantage of the opportunity and find out the answers together. Use the websites of trusted organizations such as UNICEF and the World Health Organization as sources of information. Many children are exposed to bullying and abuse at school or online for things related to Coronavirus (COVID-19). It is very important for your children to know that you are always there for them if they experience any bullying. Active bystanders are the solution to any type of bullying. Children who face bullying don't have to deal with it alone. We have to encourage them to depend on their friends and adults for help and support. Do things that appeal to them and please them when it comes to dealing with difficult emotions, start with what your son hints at, and balance between talking about the emotions that affect him and his distraction with other things that help him, especially when he feels distressed. As a family, they all participated in a game every few days or cooked together: We decided to prepare dinner together every night. We will be in two groups, and every day one of them will take responsibility for preparing dinner. There is nothing wrong with 
teenagers allowing unrestricted use of their electronic devices but without extravagance. We advise that you explicitly tell your son or teenage daughter that you understand that they have more time to tamper with their smart devices, but it is not right to let them use them and access social networking sites on them. Ask your son or teenage daughter, How are we going to solve this issue? Can you come up with a plan for your day and show me it? Then I'll tell you what I think. Finally, parents are also anxious and children feel this. I ask the parents to do what they can to control their anxiety, and not to share their concerns with their children. This means suppressing emotions, which is sometimes not easy. Especially if these feelings are putting pressure on parents. Children depend on their parents to feel safe and secure. It is important to remember that they are the passengers in this ordeal, and we are the ones driving the cart. Accordingly, if we are concerned, this feeling must not leak out to them, hindering their sense of safety during their journey.
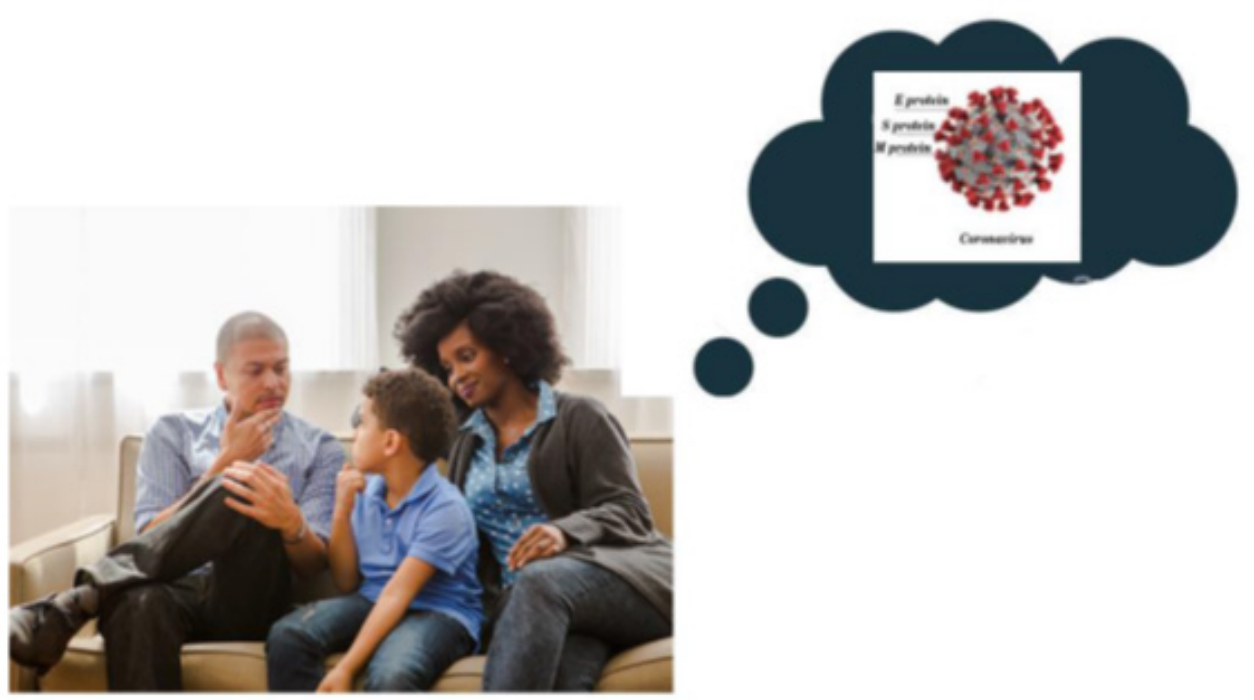

Figure 1

\section{Conflict of Interest}

The authors declare no conflict of interest.

\section{Conclusion}

In this study, we have provided many tips that can help parents on how to deal with their children in order to avoid the psychological impact of illness on them. In the form of applying these tips, it is certain that the virus will not have a psychological effect on children.

\section{References}

1. Anita T, Sarah S, Gordon T (2021) What has happened to children's wellbeing in the UK? Lancet Psychiatry 8(1): 5-6.

2. Rakhi D, Rajesh S (2021) COVID-19 offers an opportunity to reform mental health in India. Lancet Psychiatry 8(1): 9-11.

3. Novel 2019 Coronavirus Genome, 2020.

4. Fehr R, Channappanavar R, Perlman S (2017) Middle East respiratory syndrome: emergence of a pathogenic human coronavirus. Annu Rev Med 68: 387-399.

5. CDC (2019) Novel coronavirus. Wuhan, China.
6. WHO (2020) Novel Coronavirus-China. World Health Organization, Geneva, Switzerland.

7. Navas S, Weiss S (2003) Murine coronavirus-induced hepatitis: JHM genetic background eliminates A59 spike- determined hepatotropism. Journal of Virology 77: 4972-4978.

8. Drosten C, Gunthe S, Preiser W, Van der Werf S, Brodt HR, et al. (2003) Identification of a novel coronavirus in patients with severe acute respiratory syndrome. N Engl J Med 348(20): 1967-1976.

9. Pierce M, Hope H, Ford T, Hatch S, Hotopf M, et al. (2020) Mental health before and during the COVID-19 pandemic: a longitudinal probability sample survey of the UK population. Lancet Psychiatry 7(10): 883-892.

10. Pierce M, McManus S, Jessop C, Ann John, Matthew Hotopf, et al. (2020) Says who? The significance of sampling in mental health surveys during COVID-19. Lancet Psychiatry 7(7): 567-568.

11. Vizard T, Sadler K, Ford T, et al. (2020) Mental Health of Children and Young People in England 2020, Wave 1 follow-up to the 2017 survey.

12. Holmes EA, O'Connor RC, Perry VH, Tracey I, Wessely S, et al. (2020) Multidisciplinary research priorities for the COVID-19 pandemic: a call for action for mental health science. Lancet Psychiatry 7(6): 547-560.

13. Gunnell D, Appleby L, Arensman E, Hawton K, John A, et al. (2020) Suicide risk and prevention during the COVID-19 pandemic. Lancet Psychiatry 7(6): 468-471. 